\title{
IPTEKS SISTEM INFORMASI PEMBAYARAN PAJAK KENDARAAN BERMOTOR PADA BADAN PENDAPATAN DAERAH PROVINSI SULAWESI UTARA
}

\author{
Miswati Dalonto $^{1}$, Sianly Lovely Kentey ${ }^{2}$, Jantje J. Tinangon ${ }^{3}$ \\ 1,2,3 Jurusan Akuntansi, Fakultas Ekonomi dan Bisnis, Universitas Sam Ratulangi, Jl. Kampus Bahu, Manado, \\ 95115, Indonesia
}

Email : miswatidalonto95@gmail.com

\begin{abstract}
Badan Pendapatan Daerah Provinsi Sulawesi Utara are moving in taxation sector, especially in Provincial Taxes that is motor vehicle taxation. A good tax payment system needs tax payment information systems that can make it easier for taxpayers to pay the taxes. Motor vehicle tax is one of the Regional Original Revenues, so the office of Badan Pendapatan Daerah Provinsi Sulawesi Utara creates and implements the Info Pajak Kendaraan Sulut application with the purpose to facilitating taxpayers to pay the tax, because this application can already provide the motor vehicle tax information in North Sulawesi region that is the amount of PKB, SWDKLLJ, and PNBP which are accompanied by a payment code that can be used to pay the motor vehicle tax. With this application Badan Pendapatan Daerah Provinsi Sulawesi Utara can easily help the taxpayers to make the tax payments because taxes are compulsory and have to be paid for use of the needs of the country and prosperity of the people.
\end{abstract}

Keywords : system information and application, taxes, motor vehicle tax

\section{PENDAHULUAN}

Saat ini sebagian besar penduduk di Indonesia sudah menggunakan atau memiliki telepon seluler, karena mengikuti perkembangan yang ada. Telepon seluler merupakan salah satu sarana masyarakat untuk mendapatkan berbagai informasi. Telepon seluler bukan hanya dipakai untuk berbicara jarak jauh tapi juga untuk mencari informasi dari berbagai sumber. Maka Badan Pendapatan Daerah Provinsi Sulawesi Utara menciptakan Aplikasi Info Pajak Kendaraan Sulut dengan tujuan utama perusahaan membuat aplikasi ini adalah untuk memudahkan wajib pajak untuk mengetahui informasi pajak yang wajib di bayar dan juga mempermudah perusahaan untuk menjalankan tugas dan kewajiban.

Pajak Kendaraan Bermotor (PKB) termasuk dalam salah satu Pendapatan Asli Daerah (PAD). Pada saat ini zaman semakin berkembang dan semakin maju dengan berbagai teknologi yang canggih dengan berbagai persaingan yang muncul demi kemajuan suatu negara, dan dengan seiring waktu dengan berkembangnya dan bertambahnya kendaraan bermotor maka dengan adanya aplikasi Info Pajak Kendaraan Sulut Badan Pendapatan Daerah Provinsi Sulawesi Utara bisa menyebarkan infomasi lebih luas tentang informasi penunggak pajak dan memudahkan dalam memungut pajak.

\section{TINJAUAN PUSTAKA}

Definisi Pajak. Pajak adalah salah satu bentuk Kewajiban atau Iuran Rakyat yang bersifat memaksa dan harus dibayarkan atau dipenuhi oleh masyarakat (Wajib Pajak) kepada negara dengan tujuan untuk memajukan negara dan mensejahterakan rakyat.

Wajib Pajak. Wajib Pajak bisa berupa badan/orang pribadi yang memenuhi tangggung jawab atau menjalankan kewajiban dalam perpajakan berdasarkan ketentuan peraturan perundang-undangan yang telah ditetapkan Pemerintah. 
Pajak Kendaraan Bermotor. Pajak Kendaraan Bermotor (PKB) termasuk dalam pajak daerah, adapun pengertian dari pajak daerah yaitu kewajiban oleh Orang Pribadi atau Badan yang harus dibayarkan kepada daerah dilandasi oleh peraturan perundang-undangan, dengan tidak mengharapkan timbal balik secara langsung dan di salurkan untuk kepentingan rakyat demi menacapai target yang sudah ditentukan. Kendaraan Bermotor yaitu mesin yang bisa digunakan diatas tanah dan bisa membentuk suatu gaya, Pajak Kendaraan Bermotor sangat penting dalam peningkatan Pajak Daerah yang juga berdampak pada peningkatan kesehjateraan rakyat.

Sistem informasi dan aplikasi. Sistem adalah beberapa komponen yang dibentuk menjadi suatu hubungan agar supaya bisa mempermudah arus entitas demi mencapai sasaran/target. Martino (1986) menyatakan Informasi adalah: "sepotong pengetahuan yang mengandung unsur kejutan dan dapat mengalir dari satu orang ke orang lain". Jogiyanto (1995) menyatakan bahwa: "Informasi ialah data yang telah diolah menjadi bentuk yang lebih berguna dan lebih berarti bagi yang menerimanya". Inti dari pengertian diatas Informasi dapat diartikan sebagai sesuatu yang akurat yang bisa digunakan untuk mengambil sebuah keputusan yang benar supaya semua masalah dapat diselesaikan dengan cepat dan tepat. Aplikasi merupakan suatu program yang dibuat dengan fungsi untuk memudahkan orang dalam mengola suatu data demi kepentingan dan tujuan bersama agar supaya pekerjaan lebih mudah terkendali.

\section{METODE DAN PENERAPAN TEKNIK IPTEKS}

\subsection{Metode Penerapan Ipteks}

Penerapan metode ipteks yang dilakukan yaitu mengimplementasikan aplikasi Info Pajak Kendaraan Sulut pada mesyarakat untuk menyederhanakan pemungutan pajak, dan melakukan pemeriksaan terhadap perangkat lunak yang sudah dibuat apakah sudah baik untuk diterapkan kepada masyarakat.

\subsection{Teknik Penerapan Ipteks}

Penerapan Teknik ipteks adalah dengan membuat strategi dengan cara harus terjun langsung ke masyarakat untuk menyebarkan sistem informasi pembayaran pajak dalam hal ini yaitu aplikasi Info Pajak Kendaraan Sulut tersebut dan menerapkan aplikasi tersebut kepada masyarakat yang memiliki kendaraan bermotor.

\section{PEMBAHASAN}

\subsection{Gambaran Objek Penerapan Ipteks}

Badan Pendapatan Daerah Provinsi Sulawesi Utara merilis aplikasi ini tepat pada tanggal 24 Januari 2018, Pada sistem yang berlaku saat ini, wajib pajak bisa mendownload langsung aplikasi Info Pajak Kendaraan Sulut melalui play store/app store. Pada aplikasi tersebut akan dimintakan berupa identitas kendaraan berupa nomor DB, jika nomor DB tersebut sudah valid maka akan muncul pada aplikasi berupa informasi untuk pembayaran pajak kendaraan bermotor beserta dengan kode bayar yang akan digunakan untuk pembayaran pajak.

Sistem Informasi Pembayaran Pajak Kendaraan Bermotor di Badan Pendapatan Daerah Provinsi Sulawesi Utara. Badan Pendapatan Daerah Provinsi Sulawesi Utara menciptakan Sistem Informasi Pembayaran Pajak Kendaraan Bermotor dalam hal ini aplikasi yang dinamakan yaitu Info Pajak Kendaraan Sulut aplikasi ini sangat membantu dan memudahkan bagi Wajib Pajak dalam proses pembayaran pajak kendaraan bermotor karena adanya aplikasi ini Wajib Pajak sudah mengetahui berapa jumlah pajak yang harus dibayar dan sudah memiliki kode bayar secara otomatis, aplikasi ini juga bisa menjadi salah satu aplikasi yang memudahkan Kantor Badan Pendapatan Daerah Provinsi Sulawesi Utara dalam pmungutan pajak provinsi dan UPTB Samsat Manado sebagai proses pembayaran pajak, 
karena aplikasi ini memiliki sistem informasi untuk mengelola data pajak kendaraan bermotor dan aplikasi ini bisa dipasang di smartphone android untuk memudahkan para Wajib Pajak untuk mengetahui berapa pajak yang harus dibayar.

\subsection{Pembahasan}

Dengan adanya aplikasi ini dapat memberikan Informasi Pajak Kendaraan Bermotor di wilayah Sulawesi Utara yaitu jumlah Pajak Kendaraan Bermotor yang harus disetor ke kas negara dan disertai dengan kode bayar yang dapat digunakan untuk melakukan pembayaran melalui fasilitas dibank atau melalui UPTB Samsat Manado. Agar bisa diterapkan dengan baik kepada masyarakat, Kantor Badan Pendapatan Daerah Provinsi Sulawesi Utara harus memiliki strategi dengan menerapkan langsung kepada masyarakat agar supaya aplikasi ini bisa lebih dikenal dikalangan masyarakat yang memiliki kendaraan bermotor. Salah satu cara untuk mengimplementasikan kepada masyarakat aplikasi tersebut, maka para pegawai harus terjun langsung ke lapangan, salah satu yang dilakukan oleh para pegawai Kantor Badan Pendapatan Daerah Provinsi Sulawesi Utara adalah penelusuran pajak untuk mengingatkan jatuh tempo pembayaran pajak dan membagikan brosur kepada masyarakat dengan tujuan untuk memperkenalkan lebih jauh aplikasi tersebut dan mempermudah bagi wajib pajak dalam proses pembayaran pajak kenderaan bermotor. Berikut dibawah ini akan ditampilkan berupa gambaran dari model aplikasi Info Pajak Kendaraan Sulut adalah sbb :

1. Tampilan yang harus di download di gogle play store/app store

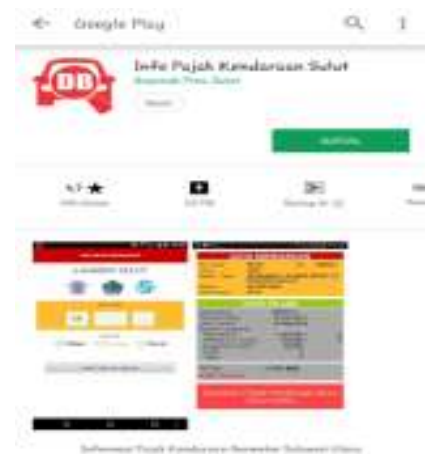

2. Tampilan saat Login

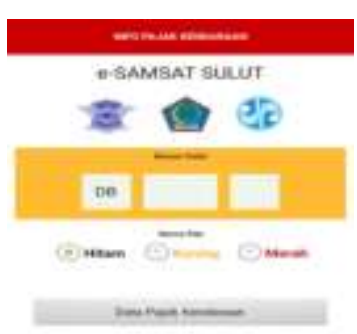


3. Tampilan Sistem Informasi Pembayaran Pajak Kendaraan Bermotor

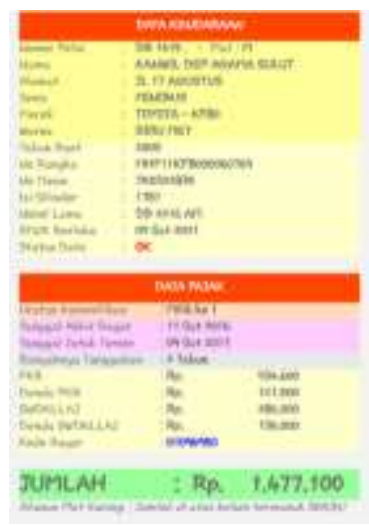

\section{KESIMPULAN DAN SARAN}

\subsection{Kesimpulan}

Sistem informasi pembayaran pajak dalam hal ini yaitu aplikasi Info Pajak Kendaraan Sulut dapat dipakai sebagai paduan untuk membayar pajak kendaraan bermotor dan juga aplikasi ini bisa memberikan informasi berupa data kenderaan, data pajak kenderaan dan juga data wajib pajak (pemilik kenderaan). Selain mempermudah wajib untuk mengetahui jumlah pajak kendaraan yang akan dibayar, aplikasi ini juga merupakan salah satu bentuk sosialisasi kepada wajib pajak akan kesadaran membayar pajak.

\subsection{Saran}

Berdasarkan penerapan ipteks ini maka diharapkan aplikasi ini dapat terus berkembang dan perlu lebih di sebarluaskan mengenai aplikasi Info Pajak Kendaraan Sulut kepada masyarakat, karena sebagian besar masyarakat belum mengetahui tentang aplikasi ini karena mengingat aplikasi ini belum lama dirilis.

\section{DAFTAR PUSTAKA}

Awaludin, I., Nurnaluri, S., dan Damayanti, W.O.R. (2017). Pengaruh Kualitas Pelayanan Dan Kepuasan Wajib Pajak Terhadap Kepatuhan Membayar Pajak Kendaraan Bermotor. Jurnal Akuntansi Dan Keuangan Fakultas Ekonomi Dan Bisnis UHO, 2(2), 109-122

Danarsi., Nurlaela, S., dan Subroto, H. (2017). Faktor-Faktor Yang Mempengaruhi Kepatuhan Wajib Pajak Dalam Membayar Pajak Mobil Dengan Diberlakukannnya Pajak Progresif Di Kota Surakarta. Jurnal Akuntansi Dan Pajak, 18(1), 45-55

Ilhamsyah, R., Endang, M.G.W., dan Dewantara, R.Y. (2016). Pengaruh Pemahaman Dan Pengetahuan Wajib Pajak Tentang Peraturan Perpajakan, Kesadaran Wajib Pajak, Kualitas Pelayanan, Dan Sanksi Perpajakan Terhadap Kepatuhan Wajib Pajak Kendaraan Bermotor (Studi Samsat Kota Malang). Jurnal Perpajakan (JEJAK), 8(1), 19

Informasi Data Di Kantor Badan Pendapatan Daerah Provinsi Sulawesi Utara.

Muchtar, M., Abdulla, M.F., dan dan Lowati, D.S. (2017). Analisis Kontribusi Pajak Kendaraan Bermotor Terhadap Pendapatan Asli Daerah Kabupaten Barito Utara. Jurnal Ilmu Ekonomi, 1(3), 385-399

Mulyawan, A., dan Novia, Dini. (2016). Aplikasi pembayaran Pajak Kendaraan Bermotor Online Berbasis Web. Jurnal Computech \& Bisnis, 10(1), 30-39

Nurbaiti, E., Susilo. H., dan Agusti, R.R. (2016). Pengaruh Implementasi Sistem Elektronik Bagi Wajib Pajak Terhadap Kualitas Pelayanan Administrasi Perpajakan (Studi Pada 
Wajib Pajak Terdaftar di KPP Pratama Malang Utara). Jurnal Perpajakan (JEJAK), 9(1), 1-9

Persada, R. (2011). Kualitas Pelayanan Pemungutan Pajak Kendaraan Bermotor Pada Kantor Bersama Samsat Kota Batam. Jurnal Ilmu-Ilmu Sosial dan Humaniora, 13(3), 284-297

Ratnasari., Nempung, T., dan Suriadi, L.O. (2016). Analisis Penerimaan Pajak Kendaraan Bermotor Di Provinsi Sulawesi Tenggara. Jurnal Progres Ekonomi Pembangunan, 1(1), $82-95$

Ruma, Z., dan Jamal, A.D. (2013). Pengaruh Pajak Kendaraan Bermotor Terhadap Pendapatan Daerah Provinsi Sulawesi Selatan Di Kota Makassar. Jurnal Economix, 1(1), 152-168

Silvia, I.A., Kumadji, S., Husaini, A. dan. (2015). Analisis Mekanisme Pemungutan Dan Penerimaan Pajak Kendaraan Bermotor Pada Kantor Samsat. Jurnal Perpajakan (JEJAK) 6(2), 1-7

Sirajuddin, H. (2017). Rancangan Aplikasi Layanan Pajak Kendaraan Bermotor Pada Dispenda. Jurnal Ilmiah “Technologi” 8(3), 182-190 